\title{
Assessing high shares of renewable energies in district heating systems - a case study for the city of Herten
}

\author{
Ali Aydemir ${ }^{1,}$, Eftim Popovski $^{1}$, Daniel Bellstädt ${ }^{1}$, Tobias $_{\text {Fleiter }}{ }^{1}$, and Richard Büchele $^{2}$ \\ ${ }^{1}$ Fraunhofer ISI, Breslauer Straße 48, 76139 Karlsruhe, Germany \\ ${ }^{2}$ TU Wien, Energy Economics Group (EEG), Gusshausstrasse 25-29, A-1040 Vienna, Austria
}

\begin{abstract}
Many earlier studies have assessed the DH generation mix without taking explicitly into account future changes in the building stock and heat demand. The approach of this study consists of three steps that combine stock modeling, energy demand forecasting, and simulation of different energy technologies. First, a detailed residential building stock model for Herten is constructed by using remote sensing together with a typology for the German building stock. Second, a bottom-up simulation model is used which calculates the thermal energy demand based on energy-related investments in buildings in order to forecast the thermal demand up to 2050. Third, solar thermal fields in combination with largescale heat pumps are sized as an alternative to the current coal-fired CHPs. We finally assess cost of heat and $\mathrm{CO} 2$ reduction for these units for two scenarios which differ with regard to the DH expansion. It can be concluded that up to 2030 and 2050 a substantial reduction in buildings heat demand due to the improved building insulation is expected. The falling heat demand in the DH substantially reduces the economic feasibility of new RES generation capacity. This reduction might be compensated by continuously connecting apartment buildings to the $\mathrm{DH}$ network until 2050.
\end{abstract}

\section{Introduction}

Germany intends to cut greenhouse gas emissions by 80 up to 95 percent in 2050 compared to 1990 . To achieve the reduction goals several states in Germany implemented climate protection laws. In North Rhine-Westphalia the "Klimaschutzgesetz NRW" was enforced in 2013. As a consequence among others local heat and energy planning is required by the communities. Such planning requires information about the future heat demand and resulting potentials for renewable energy sources (RES) heat supply, especially with regard to district heating (DH) networks. This paper is on the DH network in Herten, located in North Rhine-Westphalia.

The district heating network in Herten consists majorly of two large sub-networks. The first system provides heat for residential and public buildings located in the northern part of

\footnotetext{
* Corresponding author: ali.aydemir@isi.fraunhofer.de
} 
the city, whereas the second one provides heat for buildings located in the southern part. Both larger sub-networks are connected to each other; however capacities of this interconnection are limited creating a bottleneck. Furthermore, several island networks exist such as the island network located in the southern part providing heat for commercial buildings and plants where the heat is supplied by the local waste incineration plant. According plans from the local utility the demand in the southern part will be fully covered by heat from the waste incineration plant in future. For the northern part this will probably not the case, as the operator of the plant is negotiating also with other interested parties from neighbour cities. Furthermore huge investments are necessary to overcome the bottleneck between northern and southern part of the DH network. The northern part of the $\mathrm{DH}$ network is currently provided with heat from coal-fired CHPs. Thus, the focus of this local case study is to show pathways on how to substitute the current heat supply in the northern DH network with centralized renewable technologies.

\section{Methodological approaches}

Several earlier studies have assessed the DH generation mix without taking explicitly into account future changes in the building stock and the heat demand (cf. [2, 3). Thus our approach is constructed to fill this gap in order to show the relevance of future demand projections with regard to system design. The approach consists of three steps, combining stock modelling, energy demand forecasting and the simulation of energy technologies.

1. First, we construct a detailed residential building stock model for Herten using remote sensing together with a typology for the German building stock.

2. Second, we us a bottom-up simulation model that calculates the annual energy demand for heating and cooling based on energy-related investments in buildings to forecast the heating demand up to 2050 .

3. Third, we design a potential new mix of new renewable generation units for the DH taking hourly demand profiles into account. The mix consists of solar thermal fields in combination with large scale heat pumps. Together they are capable to substitute the current coal-fired CHPs nearly fully.

4. We finally assess the new generation mix with regard to cost of heat and $\mathrm{CO}_{2}$ reduction for two scenarios.

\subsection{Residential building stock model}

The building stock model constructed distinguishes between regional location and type of a building. To construct the building stock five main sources of information are used as follows:

- A printed map from the climate concept 2020+ fractioning the city in so-called energetic city space types 1 .

- A digital map from the land registry office containing basic (plot) areas of buildings in Herten.

- The online available GIS-system TIM-online provided by the state of North Rhine-Westphalia 5.

- The building typology for Germany prepared by the Institut Wohnen und Umwelt GmbH (IWU) in Darmstadt 6.

- The census database for Germany. In the database, the number of flats differentiated by size categories is contained differentiated by cities 7 .

The building stock is constructed in two steps. The first step was to rework the map of energetic city space types. This was based on the reason that the plot areas of buildings 
contained in the map from the land registry office do not appear to be homogenous within all areas differentiated in the map of energetic city space types. The second step was to assign to each area from the new map a building type from the building typology for Germany prepared by IWU. Therefore the new map has been compared with the map of energetic city space types and orthoimages from the TIM-online system visual. Based on this visual comparison a building type had been assigned to each area.

\subsection{Heat demand forecasting}

The present heat demand for the building stock differentiated by building type has been calculated based on data from the local utility. The local utility evaluated the energy demand of the buildings in the city by analyzing the demand for natural gas and district heating at the points of delivery to the buildings. As a result the present heat demand for the building types had been defined. Based on this heat demand and building stock projections are calculated up until 2030 and 2050 using the simulation model INVERT/EE-Lab 4. The model allows simulating the impact of current building standards and renovation on the evolution of the future building stock and the resulting energy demand. The projection is based on a current policy scenario for Germany taking the renovation of buildings, the demolition and the construction of new buildings into account. Energy-related investments are simulated based on a combination of approaches from decision theory as well as diffusion theory.

Averages of resulting rates are given in the following as indication: average rate of modernization $1.5 \%$, new construction rate $0.4 \%$, demolition rate $0.5 \%$. A substantial decrease in heat demand from about $460 \mathrm{GWh}$ in 2014 to little above $200 \mathrm{GWh}$ in 2050 can be observed. The corresponding specific thermal energy demand for space heating and hot water per year and square meter is given in Table 1.

Table 1. Estimated final energy demand for space heating and hot water $\left[\mathrm{kWh} / \mathrm{m}^{2} \cdot \mathrm{a}\right]$.

\begin{tabular}{|c|c|c|c|}
\hline Building type & $\mathbf{2 0 1 4}$ & $\mathbf{2 0 3 0}$ & $\mathbf{2 0 5 0}$ \\
\hline Detached house & 185 & 115 & 89 \\
\hline Terraced house & 150 & 97 & 81 \\
\hline Apartment building & 150 & 85 & 64 \\
\hline Large apartment building & 83 & 64 & 54 \\
\hline
\end{tabular}

\subsection{Design of RES heat generation units}

The technical detailed modelling of potential new generation units has two goals. First, technical feasible assumptions on the heat delivered to the DH by renewable energies shall be derived. This assumption shall serve for the scenario definition in chapter 3 . Second, current cost for a modelled potential new mix of RES supply units in the DH shall be indicated. This is to indicate challenges for such systems in the results section (chapter 5).

For the proper design of new generation units an hourly demand profile for the district heating network is needed. This is calculated based on the given annual consumption data for the community by using energyPRO 8. In principle the profile is generated by fractioning the annual demand of the district heating network into hourly demand values. To do so $80 \%$ of the district heating demand is modelled to be linear dependent on ambient temperatures accounting for space heating. A threshold value of $15^{\circ} \mathrm{C}$ ambient temperature is used. Above this threshold, no space heat is demanded. The residual $20 \%$ - share of the district heating demand is modelled independent from ambient temperatures, assuming that it is mainly due to residential hot water demand. 
Technology and cost assumptions are used to model the heat generation of the potential new thermal supply units in the $\mathrm{DH}$ and to calculate the resulting levelised cost of heat $(\mathrm{LCOH})$. For the calculation of the $\mathrm{LCOH}$ the annuity method is applied and it is defined based on equation (1) and (2). CRF represents the capital recovery factor which is derived by taking the interest rate $(i)$ and economic lifetime of the unit $(n)$ into account. $C_{I}$ represents the investment necessary to buy the unit and $\mathrm{C}_{O \& M}$ the corresponding annual cost for operation and maintenance. Finally HS stands for the heat supplied by the unit to the $\mathrm{DH}$ within a year.

$$
\begin{aligned}
& \mathrm{LCOH}=\left(\mathrm{CRF} \cdot \mathrm{C}_{\mathrm{I}}+\mathrm{C}_{\mathrm{O \& M}}+\mathrm{C}_{\text {fuel\&tax\&levies }}\right) \div \mathrm{HS} \\
& \mathrm{CRF}=\left(\mathrm{i} \cdot(1+\mathrm{i})^{\mathrm{n}}\right) \div\left((1+\mathrm{i})^{\mathrm{n}}-1\right), \text { with }
\end{aligned}
$$

For the potential new mix of renewable generation units a solar district heating system together with a large scale heat pump is chosen. For the solar district heating system this refers to solar thermal collector fields in combination with pit storages. Capital costs are taken from a guideline 10. In the guideline capital cost for various system sizes are given. Based on this we modelled cost functions setting system sizes into relation to capital cost. Both cost functions reflect economies of scale, i.e. larger fields or storages have lower specific cost than smaller ones. Costs of land are derived from a Geographical Information System from the state North Rhine-Westphalia 11.

Herten and is neighbour cities are former coal mining cities. As a consequence a local mining company annually pumps over 100 million cubic meters of water to the surface in the region to guarantee the stability of the ground and the safety of the drinking water. The temperature of the pit water is around $20^{\circ} \mathrm{C}$ and can serve as a heat source for large scale heat pumps. To define technical parameters for the heat pump (such as the COP) two existing case studies are used as reference 12. The first case study is located in Bochum. In the study a heat pump using pit water as heat source has already been erected and tested. The second case study is from Helsinki. In the study sewage water is used as heat source for a large scale heat pump in the DH network 13. Capital cost for heat pumps are based on the "Technology Data for Energy Plants" database published by the Danish Energy Agency 14. For the heat pumps we have in contradiction to the solar fields no cost function, so that no economies of scale are taken into account. Electricity cost for 2011 are based on Eurostat electricity prices for industry (consumption band: ID, Excluding VAT and other recoverable taxes and levies, 113.9 EUR/MWh) and price projections are based on own calculations.

The system design is carried out by first defining the size of the solar thermal collector field including storage volume and afterwards defining the thermal capacity of the heat pump. Please note that in the project system designs has been carried out for several subnetworks. However, as the behaviour is equivalent for all sub-networks the description in the following is only on one sub-network. For the design two criteria are applied, the $\mathrm{LCOH}$ and the heat delivered to the DH. The heat delivered to the DH by the solar field and the heat pump is set in reference to the overall demand and called heat fraction. The design approach is stepwise as described in the following.

- First, the solar field and storage size is set, so that the LCOH of the solar thermal collector field including storage is minimal (including storage).

- Second, the thermal capacity of the heat pump is set, so that the present heat fraction is maximized for the combined system as much as possible.

The share of the heat provided by the solar field compared to the overall demand (solar fraction) for varying field and storage sizes is given in Fig. 1. Referred to the heat produced, the LCOH for the solar size finally chosen is around $22 \mathrm{EUR} / \mathrm{MWh}$. 


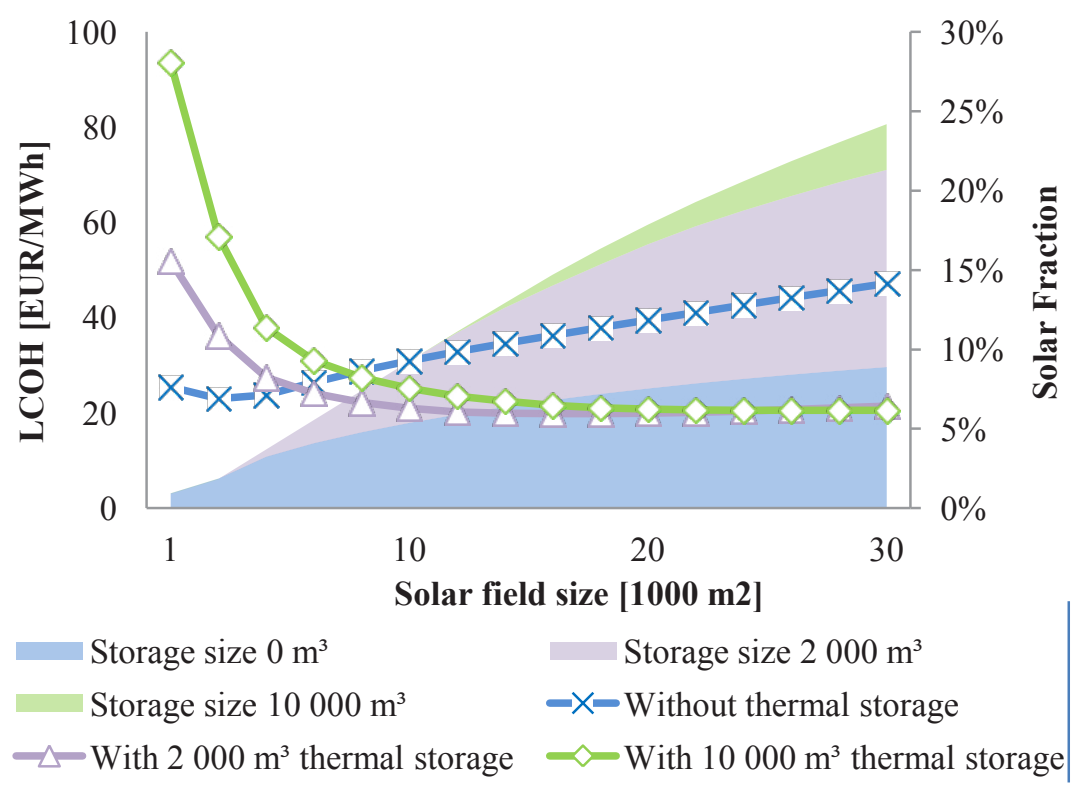

Fig. 1. Exemplary solar field analysis for one sub-network.

For the heat pump the maximum share of heat delivered to the $\mathrm{DH}$ network compared to the overall demand reaches a maximum at approximately $85 \%$, which is based on two reasons. The first reason is that the solar field has a lower $\mathrm{LCOH}$ than the heat pump. As the final objective set is to minimize cost whenever it is possible, the solar field and storage are preferred in the operation strategy. The second reason is that the demand during very cold hours requires high inflow temperature in the district heating network, which can't be supplied by the heat pump. However, this is the minor reason. Modelling the heat pump without solar fields and heat storages a maximum heat pump fraction of approximately $99 \%$ can be achieved based on ambient temperatures in the city in 2011. Referred to the heat produced, the $\mathrm{LCOH}$ for the heat pump designed is around 70 EUR/MWh. Including thermal losses in the distribution system the overall LCOH for the combined system (solar + heat pump) is around $75 \mathrm{EUR} / \mathrm{MWh}$. Both based on the demand in 2011.

It is obvious that the design approach chosen tends on the one hand towards relatively small solar thermal collector fields and on the other and towards high capacities for the heat pump. The argumentation for this approach was to fully substitute the heat delivered by the coal fired CHPs by the new units also for present conditions. However, the heat pump has higher LCOH than the solar thermal collector field. Thus lower capacities for the heat pump result in lower overall LCOH for the combined system. This is even more relevant behind the background that the heat demand forecast predicts a substantially falling demand in future. Consequently it is debatable if a smaller heat pump capacity than chosen might make more sense. A better way to size the heat pump with regard to $\mathrm{LCOH}$ might be to define the thermal capacity, so that the capacity factor is maximised with regard to the future demand projected (i.e. with regard to the demand in 2030 or 2050).

\section{Scenario definitions}

Four scenarios described in the following are used to calculate future $\mathrm{CO}_{2}$ reduction and $\mathrm{LCOH}$ for the new units designed (solar + heat pump). The LCOH are calculated for a so 
called socio-economic perspective $(1.5 \%$ discount rate, no taxes and profit margins, no external costs). Thus, this perspective only reflects cost without taking possible earnings required by operators into account. To paint a whole picture the residual heat demand not covered by the DH network is also taken into account. The assumed share of heat generation technologies supplying the residual (de-central) heat demand is based on projections from 15 for Germany. In general the scenarios differentiate between assumptions on the DH network expansion and mix of supply units. A summary is given in Table .

- Scenario 1: No additional district heating expansion. The relative share of connected/supplied houses remains constant as in the present. $95 \%$ of the demand in the northern DH network is supplied by the heat pump and solar thermal fields. The southern DH network is supplied by the waste incineration plant. Furthermore the heat demand for residential housing develops as forecasted in 2.2.

- Scenario 2: Moderate district heating expansion. The number of connected/supplied houses is increased, so that the final energy demand for district heating from the residential housing in 2050 equals more or less to the demand in 2011. The share of the district heating network increases from $28 \%$ in 2011 to 36 and $68 \%$ in 2030 and 2050 respectively. Heat generation units and assumed heat demand forecast are the same as in Scenario 1.

- Forecasted: The district heating network is not expanded and still supplied by the existing coal-fired CHP plants. The residential heat demand forecast is the same as in Scenario 1.

- No renovation: The district heating network is not expanded and supplied by the existing coal-fired CHP plants. The heat demand forecast is not the same as in Scenario 1 as the heat demand stays constant as in 2011. This reflects a scenario where households do not renovate.

Table 2. Scenario overview.

\begin{tabular}{|c|c|c|c|c|}
\hline & $\begin{array}{c}\text { Heat Sources } \\
\text { DH } \\
\text { (central) } \\
\end{array}$ & $\begin{array}{c}\text { Heat Sources } \\
\text { de-central }\end{array}$ & $\begin{array}{c}\text { Heat } \\
\text { demand } \\
\text { forecast }\end{array}$ & $\begin{array}{c}\text { DH } \\
\text { expansion }\end{array}$ \\
\hline Scenario 1 & \multirow{2}{*}{$\begin{array}{l}\text { North: } 95 \% \mathrm{HP}+\text { solar } \\
\text { South: waste incineration }\end{array}$} & \multirow{4}{*}{$\begin{array}{l}\text { As projected in } \\
15 \text { for Germany }\end{array}$} & \multirow{3}{*}{$\begin{array}{l}\text { Reduction as } \\
\text { modelled in } 2.2 \text {. }\end{array}$} & no \\
\hline Scenario 2 & & & & yes \\
\hline Forecasted & \multirow[b]{2}{*}{ As today } & & & no \\
\hline $\begin{array}{c}\text { No } \\
\text { renovation }\end{array}$ & & & No reduction & no \\
\hline
\end{tabular}

To calculate the capital cost for the expansion of the district heating network a formula based on Persson et al. 16 is applied, which combines both heat and building density. In Persson et al. the formula is used to analyze potential capital cost for district heating expansion for areas with different heat building densities within a city (plot ratios) under varying market shares for district heating.

\section{Results}

In Fig. 2 the $\mathrm{LCOH}$ for the new system designed and the $\mathrm{CO}_{2}$ reductions for residential buildings compared to 2011 are presented for the scenarios. It can be seen that the LCOH for the modelled new generation mix (heat pump + solar) strongly depends on the future district heating demand. In Scenario 2, where the density is increased costs are 10 to $35 \%$ lower than in the corresponding Scenario 1 with no DH expansion. 
$\mathrm{CO}_{2}$ reductions range around $60 \%$ for 2030 compared to 2011 for scenarios, which take the forecasted demand reduction in residential housing into account (Scenarios 1\&2 and Forecasted). From this reduction 33\%pts. are due to renovation. Further $26 \%$ pts. are mainly due to exchanging de-central heat devises as projected in 15 for Germany. This share is quite large, because in Herten still large shares of residential heating are based on heating oil and coal (21\% in 2011). Finally, in Scenario $1 \& 2$ further $4 \%$ pts. reduction are achieved by the new modelled generation units in 2030 .

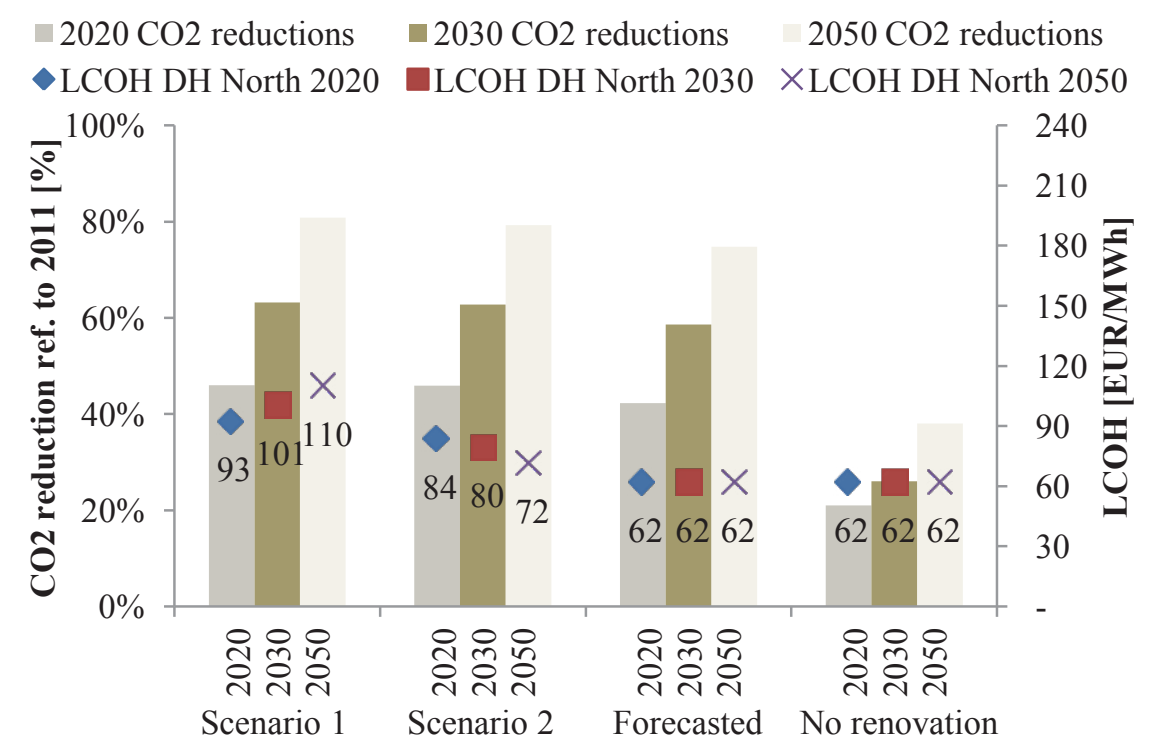

Fig. 2. $\mathrm{LCOH}$ for new units and $\mathrm{CO}_{2}$ emissions reduction per scenario.

\section{Conclusions}

Up to 2030 and 2050 a substantial reduction in buildings heat demand due to improved building insulation is expected. The falling heat demand in the system can substantially reduce the economic feasibility of new RES generation capacity, particularly for systems with high upfront cost such as heat pumps. Nevertheless, the reduction in heat demand can be compensated by continuously connecting apartment buildings to the DH network as there is still enough heat demand in the whole community. This is a lever to compensate the increasing price. Including solar thermal fields reduces the LCOH substantially compared to using heat pumps only. Anyhow, the $\mathrm{LCOH}$ for the combined system is by far higher compared to the reference system. The major reason for that is the relatively high LCOH for the large scale heat pump. Thus, further evaluations should focus on how to reduce $\mathrm{LCOH}$ for heat pumps. Such evaluations might cover technical and political means. For example it could be examined how to further improve the overall system efficiency by improving components and system design. However, as in our case study round about twothirds of the $\mathrm{LCOH}$ for the large scale heat pump is determined by electricity cost the relevance of political means should not be underestimated. In the electricity cost assumed several levies are included implicitly by using a statistical value from Eurostat for a group based on consumption ranges. These levies might have large influences on the LCOH calculated. Finally, the gas infrastructure is a major competitor to DH expansion, especially with regard to the erection of new buildings and renovation. As a higher density of the DH 
network decreases the cost of RES in DH by tendency, the competition is from major relevance and should be analyzed more in detail in future for Germany.

\section{Acknowledgements}

This paper is based on work packages carried out within the project progRESSHEAT. The project is funded by the the European Union's Horizon 2020 research and innovation programme. Furthermore we thank the anonymous reviewer for the helpful comments increasing the quality of this paper.

\section{References}

1. W. Rüdiger, B. Tenberg, Hertener Klimakonzept 2020+ Ein Masterplan für 100\% Klimaschutz in Herten, Jung Stadtkonzepte (2013)

2. A. Dalla Rosa, R. Boulter, K. Church, S. Svendsen, Energy 45, 960-974 (2016)

3. M. Köfinger, D. Basciotti, R.R. Schmidt, E. Meissner, C. Doczekal, A. Giovannini, Energy 110, 95-104 (2016)

4. Homepage of Invert/EE-Lab model, Internet http://www.invert.at/ (accessed on 23.02.2017)

5. TIM-online, Geographical Information System, Internet: http://www.timonline.nrw.de/tim-online/initParams.do?role=default (accessed on: 23.02.2017)

6. Institut für Wohnen und Umwelt, Deutsche Gebäudetypologie - Systematik und Datensätze (2005)

7. Statistisches Bundesamt: Zensus 2011: Gebäude und Wohnungen (2014). Internet: https://www.destatis.de/DE/Methoden/Zensus_Zensus.html(accessed on: 23.02.2017)

8. Homepage of energyPRO model. Available at: http://www.emd.dk/energypro/ (accessed on 23.02.2017)

9. J. Conrad, T. Schmid, C. Pellinger, Erzeugung von Fernwärmelastgängen aus Temperaturprofilen, Energiewirtschaftliche Tagesfragen 9, 52-54 (2015)

10. J.E. Nielsen, R. Battisti, Solar district heating guidelines, Feasibility study, (2012), Internet: www.solar-district-heating.eu (accessed on: 23.02.2017)

11. Aktuelle Informationen zum Immobilienmarkt in NRW: http://www.boris.nrw.de/ (accessed on: 23.02.2017)

12. C. Geimer, Thermal heat from pit water, FIZ Karlsruhe (2013)

13. S. Foster, J. Love, I. Walker, M. Crane, Heat Pumps in District Heating - Case Studies, DEEC (2016)

14. The Danish Energy Agency, Technology data catalogue, downloaded in March (2016) Internet: https://ens.dk/en/our-services/projections-and-models/technology-data

15. Öko-Institut; Fraunhofer ISI: Klimaschutzszenario 2050. 1. Modellierungsrunde. Hg. v. Bundesministerium für Umwelt, Naturschutz, Bau und Reaktorsicherheit. ÖkoInstitut e. V.; Fraunhofer-Institut für System- und Innovationsforschung ISI (2014)

16. U. Persson, S. Werner, Appl. Energy 88, 3, 568-576 (2011) 